\title{
Research on Logistics Services in E-commerce
}

\author{
Zhang Qiang \\ School of Economic and Management \\ Shengyang Aerospace University \\ Shengyang, China \\ Zhangqiang@sau.edu.cn
}

\begin{abstract}
The emergence of e-commerce has a great impact on the traditional logistics. At present, the rapid development of e-commerce is inseparable from business flow, capital flow, logistics and information flow. Among them, the most practical logistics that connects the whole process becomes particularly important. China's ecommerce starts late yet has grows rapidly, which has proposed increasingly high requirements over logistics. Also, with fierce e-commerce business competition, logistics enterprises gradually improve their service quality, make innovation for service projects, and strive to take the lead in competition. Further research of e-commerce logistics services not only promotes the development of e-commerce industry, but also provides a direction for the development of logistics enterprises.
\end{abstract}

Keywords-E-commerce; Logistics Services; Service Bottlenecks; Service Quality1

\section{INTRODUCTION}

The biggest problem we face today is the quality and service problem of logistics that connects between ecommerce and customers. As a service sector, logistics has been in progress. However, e-commerce develops quickly, and people contacts with e-commerce come more and more frequently, making consumers have increasingly high requirements over logistics services. The deeper reasons lie in restrictions of development level and development stages of China's logistics industry. China's service industry is featured by late start and imbalanced development, logistics is in an awkward position between the secondary industry and the tertiary industry, so it does not achieve long-term good development. Until recent years, it rises to be a popular sector. The sharp growth amount of online shopping brings more opportunities and greater challenges to logistics. Besides, logistics is expected to be faster and better. According to China Ecommerce Research Center, consumers mainly complain for slow arrival, insist accepting goods after signing and poor customer service attitudes, causing consumers to feel greatly reduced satisfaction degree of e-commerce. At present, e-commerce enterprises and logistics enterprises need to focus on thinking how to improve the consumer shopping experience through logistics services. It is an important means for enterprises to improve customer satisfaction and market competitiveness by understanding the key roles of logistics in e-commerce, knowing about consumers' online shopping requirements over logistics and improving the satisfaction of logistics distribution services.

\section{CURRENT LOGISTICS SERVICE BACKGROUND UNDER E-COMMERCE}

With the rapid development of the network economy, more and more enterprises achieve e-commerce transactions through the network platform. However, to carry out business activities in the electronics supply chain, e-commerce environment, trading enterprises cannot truly achieve integrated operation of business flow, information flow, capital flow and logistics. In particular, after enterprises achieving online transactions, the logistics distribution problems are often separated. On one hand, the trading sides are featured by geographical dispersion, diverse demands, multiple one-time tasks of sales or procurement activities and relative complex logistics problems. On the other hand, China is facing imperfect and unsound existing social logistics service system, and the third-party logistics that targets for network distribution has inadequate service capacity.

Currently in major carrier of e-commerce public platform that provides trading enterprises with ecommerce services especially lacks participation and supports from high-quality third-party logistics enterprises, resulting in trading enterprise cannot enjoy the convenient one-stop efficient e-commerce services. Therefore, how to improve service capabilities of third-party logistics enterprises, transform marketing concept to enter ecommerce and how to effectively collaborate with public platform to promote the development of e-commerce logistics are emergent issues to be solved. Backward development of logistics services and value-added services has become a bottleneck hindering the development of neutral e-commerce platform.

\section{LOGISTICS SERVICE FEATURES IN E-COMMERCE}

As an emerging industry, logistics in e-commerce has the following features:

\section{A. Large Order Quantity and Small Batch}

Compared to other manufacturing industries and automotive industry, owing to the special property of logistics service objects in e-commerce industry, ecommerce enterprises have relatively large number of orders, relatively small amount per unit; since B2C ecommerce product categories tend to be diversified, an order often contains multiple product categories, leading to difficult sorting; category diversification results in hard standardization, mechanization of packaging and thus higher requirements over logistics. 


\section{B. Higher Requirements over Timeliness}

Different from traditional stores, consumers cannot immediately get favorite products, and they have to wait for some time.

\section{Wide Service Scope}

The service object of e-commerce is the whole country or even any place in the world that can place orders online, which means the service scope of logistics service providers is the whole country or the world.

\section{Higher Quality of Employees}

The logistics distribution employees serving for ecommerce directly contact consumers, representing corporate culture and image, and they are major evaluation basis for consumers' direct intuitive feelings.

\section{ANALYSIS OF E-COMMERCE LOGISTICS DEVELOPMENT STRATEGY}

To hold a position and achieve certain advantages in the logistics industry and fierce market competition, logistics enterprises should focus on customer service, put customers first, give full play to their own advantages, constantly update the service contents on the basis of transportation, warehousing, distribution and other functional services, and provide customers with differentiated, personalized logistics services, which can carry out the following strategies:

\section{A. Logistics system should strengthen integration with e- commerce enterprises}

Logistics distribution service has been an important link of e-commerce development. Logistics services of self-built logistics system have two main options. The first option is that enterprises spend lots of money in building complete logistics system, and achieve synchronized development of e-commerce and logistics, such as Jingdong Mall, Suning Tesco, VANCL and so on. Another option is that logistics enterprises rely on their own express advantages to develop e-commerce, effectively save warehousing, packaging, distribution costs, and develop the longitudinal deepening profit model, such as SFbest and the Express Railway Express mall, which adopt the pattern of logistics first and then e-commerce. According to research and statistics, the logistics service qualities of Jingdong Mall and VANCL are significantly higher than ecommerce enterprises relying on third-party logistics, such as Taobao. Besides, for the e-commerce platform with combination of self-operation and third-party such as Jingdong Mall, its proprietary logistics services are significantly better than the outsourced logistics services. The comparison shows that in order to cope with various changes, self-built e-commerce platform logistics is an effective choice. Another successful pattern, such as SFbest shopping platform, sticks to the service concept and logistical advantages of SF Express, strives to shorten the supply chain with logistics, uses the global SF networks, establish a synchronized global procurement system, rely on SF Group's logistics advantage, and quickly realize the operation model of delivering from the source to consumers within 24 hours. The success of the two patterns show that in order to provide better e-commerce and logistics services, e-commerce and logistics enterprises are complementary and mutually beneficial, so it is a major trend of future development to strengthen the integration .

\section{B. Reduce cargo damage and shortage rate of cargo, and improve the logistics quality system}

To solve the cargo damage, loss, change and other problems appeared in the service process, lost, enterprises should first achieve reasonable claims over the damaged cargo, improve the quality control and management works during the shipment, and strengthen the supervision of the shipment. Express delivery enterprises should intensify efforts to realize software and hardware construction, make the greatest efforts to facilitate customers, achieve high quality management via hardware and software platforms, reduce damage to customer articles in the delivery process, and minimize the cargo damages. Meanwhile, for damaged goods, enterprises should take the initiative to take responsibility, and provide reasonable claims for customers.

Improvement of logistics services quality is an important guarantee for the development of the logistics industry. At present, the most advanced quality management system is internationally certified ISO9000 quality management system. To improve logistics service quality, enterprises should build an effective quality management system, and ISO9000 quality management system is the most effective, most advanced and standardized quality management theory and method. Although many logistics enterprises have built the quality management system, their operation efficiency is dissatisfactory because of inadequate execution and supervision efforts. Therefore, the logistics enterprises should conform to ISO9000 standards, build a service quality management system, enable the organizations, processes, procedures and resources of quality management to form an organic whole, and build an effective logistics service quality control mechanism, so as to implement service quality policy, achieve the quality objective, truly satisfy customer needs and expectations to the maximum degree, and enhance customer satisfaction.

The service quality management system of logistics enterprises involves all resources and elements affecting the service quality as well as the whole process of service implementation. When operating the logistics service quality management system, logistics service implementation process is the most important, including logistics services marketing process, logistics service design process, logistics service delivery process and process of evaluation and improvement of logistics service performance. Logistics enterprises improve and enhance their service quality by repeating the above processes. Therefore, enterprises should strengthen the process control, supply the best logistics services with appropriate logistics costs, and thus improve the overall quality of logistics enterprises.

\section{Further expand logistics services and enhance service value}

To create greater value in the logistics chain, it is necessary to achieve the transition from traditional logistics services to value-added logistics services. Traditional logistics service refers to the process of goods circulation through transportation, warehousing, 
distribution and other functions. Labor costs and equipment costs account for most of the costs, the profit is low, so enterprises can only rely on increased shipment volume and distribution volume to add profits. It is difficult for logistics enterprises to separate the levels for the same services, so they face fierce market competition. Today, it is essential to achieve the integrated logistics service pattern, launch varied services according to the needs of different customer groups, mainly launch personalized value-added services, and increase market competitiveness.

By transiting from traditional logistics services to value-added services, integrated innovative services, management services of participated logistics customers, enterprises may complete the upgrade of the entire logistics system. More and more logistics enterprises have discovered the value-added services. Service improvement is the New World to achieve profitable growth. Besides, enterprises have launched new businesses and new services for different groups, which is progress made in the logistics industry. However, in order to build integrated logistics services, enterprises must focus on the logistics service level. Increased speed will necessarily increase customer satisfaction, but if enterprises blindly focus on this point, distribution costs will be greatly increased, the total profits will be declined. However, some customers have high demands over this. Amazon has thus taken a good measure, that is, introduce VIP customer service, and enjoy the fastest delivery service and the right to give priority to experience the new service. It is necessary to pay the annual fee to become a VIP customer, which guarantee the capital pool of express service and improve customer satisfaction. As a result, more values could be created by further expanding logistics services.

\section{Sustainable Service-oriented Logistics Development Path}

China's logistics industry has entered a new stage and face new opportunities. The industry should seize the strategic opportunities to expand domestic demand especially consumer demand, and play greater roles in effectively meeting consumer demand, reduce circulation costs and improve circulation efficiency. Besides, the industry should grasp the innovation-driven strategic opportunities, encourage enterprises to speed up model innovation, technological innovation and service innovation, and form new power for technological progress and management innovation. Meanwhile, the industry should seize the strategic opportunity of an open economy, create an international network of logistics services, and provide logistics supports for other industries to "go out". In addition, the industry has to implement green logistics, recycling logistics, low-carbon logistics, and walk a sustainable development path.

Modern logistics should focus on reducing the total logistics cost and improve the efficiency of logistics operation. Logistics enterprises should transit from the traditional logistics service provider with single function and price competition to supply chain management service provider with systems integration and cooperation, and enhance core competitiveness of enterprises. Besides, guide the industry to transit from a cost-driven extensive development with speed priority to innovation-driven intensive development pattern with benefit priority, and improve the quality and efficiency of the logistics industry.

Logistics enterprises should grasp the strategic management, comply with the market demand, shorten the front with inadequate competitiveness, adjust the business structure and organizational structure, focus on market segments, clarify their positioning, and strengthen links with core customers. Besides, logistics enterprises should grasp the service management, pay attention to fine, highend, personalized services, and promote lean logistics service pattern. Logistics enterprises should pay close attention to new trends of emerging technology, new energy, energy conservation, logistics information and other technological development fields, actively participate in the pilot demonstration, and strengthen technology transformation efforts. Moreover, logistics enterprises should make full use of modern advanced information technology, create public logistics service platform, transform the traditional operation pattern through green logistics technology, and realize coordinated development of environmental protection and efficiency improvement.

\section{CONCLUSION}

With the rapid development of e-commerce, logistics grows quickly. While the number of courier enterprises is on the rise, various logistics service issues have become even more prominent, such as lack of standardized management, disjoint from e-commerce business needs, and imperfect system of related industries. In order to promote the development of e-commerce market, increase market competitiveness of logistics enterprises and ultimately promote the progress of the service industry, logistics enterprises must strengthen the construction of ecommerce logistics services, standardize relevant industrial systems, and build a sound scientific supply chain mechanism. In such a way, logistics enterprises can continuously improve the service quality, help e-commerce enterprises become bigger and stronger, and promote the common prosperity of the whole industry chain.

Based on relevant literature, this paper concluded the current situation, problems and strategies of logistics service under e-commerce. This paper aims to improve competitiveness and influence by solving the problem of logistics link. The paper has mainly finished the following works:

- Describe the concept and related basic content of e-commerce logistics;

- Describe the current situation of development of domestic and international e-commerce logistics services;

- Point out the problems of e-commerce logistics services by analyzing the enterprises that typically involve e-commerce logistics;

- Point out factors and viable suggestions for the proposed problems.

By comparing domestic and international logistics services and analyzing domestic advanced e-commerce logistics enterprises, it is obvious that logistics distribution is being systematic, international, social and information. Future e-commerce and logistics will provide more convenience for us, but the logistics services problems still hinder the development of e-commerce and logistics development. Now some large e-commerce enterprises and 
logistics enterprises have realized the importance of service, e-commerce logistics service will definitely develop quickly, adding more colors to people's life.

\section{REFERENCES}

[1] Huang Gang. Integration and Synergy is King: Business Value [J] E-commerce and Logistics.2011 (6)

[2] Zhang Zhenbin. Dock with E-coomerce and Logistics Technology and Application: Freight Vehicles [J] Create the Distribution Platform.2011

[3] Li Jingyu. Lean in Integration - E-commerce is developing, logistics should be gelivable - Interview Deputy Director of Business Trade Circulation Development of Ministry of Commerce Wang Xuanqing for China Logistics [J]. E-commerce and Logistics.2013(10).

[4] Liu Xiaogeng, Wang Hongwei, Fei Hanhua. Logistics Service Innovation Model based on Industry Linkage [J] Logistics Engineering and Management.2013(10).

[5] Liu Fuzhu. Analysis of Logistics Services Development under China's E-commerce [D]. Science \& Technology Economy Market. 2012 (5).

[6] Liu Luxing. Focus and Profession are a king: Information and Computer [J]. E-commerce and Logistics.2012(7)

[7] Feng Tang. Being Closely Related and Mutually Independent to achieve win-win at the Logistics Era $[\mathrm{J}]$ E-commerce and Logistics.2013(8)

[8] Zheng Bing, Dong Dahai, Jin Yufang. Review of the Foreign Study on Logistics Service Quality [J] Journal of Management.2011(3)

[9] Wang Shaojun. E-commerce and Logistics [M]. Shanghai Jiaotong University Press, 2012
[10] Liu Juan. Discussion on Emergence of Small Cross-border Trade E-commerce Problems - E-commerce and Logistics Service Innovation at the Post Financial Crisis Era [J] Practice in Foreign Economic Relations and Trade.2012(2)

[11] Li Qi. Stones from Other Hills - Some Successful Practices of Foreign E-commerce $[\mathrm{J}] \quad$ International Business \& Technology.2011(3)

[12] Ren Fengxiang, Dai Xiaohuan. Enlightenment of Enlightenment Foreign Books Logistics Pattern under E-commerce Environment [J] Market Modernization.2011

[13] Jimmy Ng.E-commerce in Shipping and Logistics in the Pearl River Delta Asia Navigation Conference 2005[C].2013(8).

[14] FENG Yi-xiong,ZHENG Bing,TAN Jian-rong.Exploratory study of logistics service quality scale based on online shopping malls.[D].2013(6)

[15] contributed by Pierre Latrille.DEFINITION OF "LOGISTICS SERVICES" PROPOSED BY HONG KONG CHINA.[J]《中国 远洋航务公告》.2012（7）

[16] contributed by Pierre Latrille.DEFINITION OF "LOGISTICS SERVICES" PROPOSED BY HONG KONG CHINA.[J]China Ocean Shipping Monthly.2012(7) 